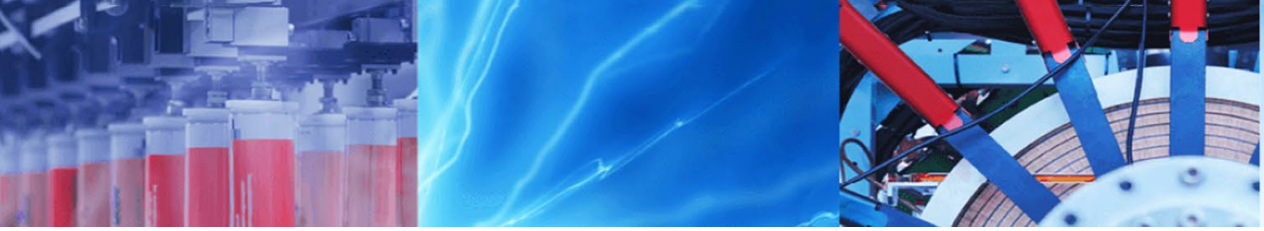

Research Article

\title{
Screening of eighteen polyphenolic compounds in different carob pekmez by green capillary electrophoresis method
}

\author{
Senem Şanlı1 [D $\cdot$ Onur Güneşer ${ }^{2} \cdot$ Sinem Kılıçarslan ${ }^{2} \cdot$ Nurullah Şanlı $^{3}$
}

Received: 1 November 2019 / Accepted: 2 March 2020 / Published online: 7 March 2020

(c) Springer Nature Switzerland AG 2020

\begin{abstract}
Carob pekmez, a traditional concentrate, has long been produced from Ceratonia siliqua L. for human consumption in Turkey. Although it is already known that carob pekmez contains several classes of polyphenolic substances, a comprehensive analysis of these compounds has not been conducted individually by capillary electrophoresis. Therefore, the polyphenolic compounds were extracted, and a sensitive, green, dependable, simple and rapid method based on capillary electrophoresis with diode array detection was developed for identification and determination of eighteen polyphenolic compounds in five different carob pekmez samples. The effect of separation voltage and $\mathrm{pH}$ of the buffer were investigated for determination of optimum conditions. The eighteen compounds were analyzed and fifteen compounds were determined within 17 min without using organic modifier. The developed method was successfully applied to the determination of polyphenolic compounds in five different carob pekmez samples with satisfactory recoveries. As a result of analyses, four major compounds could be determined (gallic acid, vanilic acid, gentisic acid and luteolin) in carob pekmez samples.
\end{abstract}

Keywords Capillary electrophoresis · Carob pekmez · Green chemistry · Polyphenolic compounds

\section{Introduction}

Carob bean is the fruit of Ceratonia siliqua L., belonging to the Leguminosae family. The tree has been widely cultivated in the Mediterranean region and Southwest Asia for many years [1, 2]. The carob bean consist of two main parts: the pod and the seeds [3]. Core shells, which are also used as a raw material for production of traditional molasses syrup concentrate produced in Turkey. Carob pod has high content of carbohydrates ( $45 \%$, sucrose at more than $30 \%)$, appreciable amounts of protein (3\%) and low levels of fat $(0.6 \%)$ [4]. It is a natural sweetener similar to chocolate with a taste and appearance and is often used as cocoa or chocolate substitute [5].

Pekmez was produced with different techniques considering the fruit types used in production. For the production of carob pekmez, the fruits (carob) are collected from the trees and then granulated using a wooden mortar. The granular carrots and water are then equally placed in open containers for 3 days to extract the soluble materials. The extract is filtered to remove solid materials. It is then boiled under stirring to concentrate to $72^{\circ}$ Brix in an open vessel. The concentrated product shows various colors ranging from light brown to dark brown depending on the concentration process [6]. It is hermetically filled into glass jars. The final product is called carob pekmez.

In recent years, carob molasses consumption has increased rapidly due to its beneficial compounds such as $\mathrm{K}, \mathrm{Ca}, \mathrm{Fe}, \mathrm{P}$ and $\mathrm{Mg}$ minerals [7]. Moreover, carob molasses can be considered a functional nutrient due to its rich phenolic content $[8,9]$. In addition, roasted

Senem Şanlı, senemkamacisanli@gmail.com | 'Department of Chemistry, Faculty of Science and Arts, Usak University, Uşak, Turkey. ${ }^{2}$ Department of Food Engineering, Faculty of Engineering, Usak University, Uşak, Turkey. ${ }^{3}$ MuratBey R\&D Center, Uşak, Turkey. 
carob pods are used to produce carob powder, which is a chocolate or cocoa substitute [5].

Polyphenolic compounds which can act as antioxidants are non-nutritive but biologically active secondary plant metabolites. These compounds can be found in many plant-derived foods and beverages and are widely distributed in the Plant Kingdom. Acceptability of fruits and vegetables for human consumption may be affected by their phenolic content [10]. Interest in the role of phenolic antioxidants in human health has led to research on the separation and characterization of active phenolic compounds in various plant-derived foods [11-13].

Today, the most important problem in the world is probably environmental pollution. To solve this problem, most of the studies have focused on the development of environmentally friendly methods and techniques or green processes. These methods, techniques and practices are known as green chemistry [14]. "Green Chemistry is the use of chemistry techniques and methods that reduce or eliminate the use or generation of feedstock, products, by-products, solvents, reagents, etc. that are hazardous to human and animal health or the environment." It also includes the use of sustainable raw materials and energy resources. It is trying to reduce pollution at the source $[15,16]$. A lot of chemicals materials are used in laboratory applications and produce large quantities of hazardous materials or waste in various forms $[17,18]$. Clean, fast and safe analytical methods and procedures need to be developed to prevent pollution. In addition, the amount of waste need to be reduced for environmental health and safety.

There are number of researches about rheological properties, antioxidant activity, chemistry and total polyphenolics of carob pekmez $[6-9,13]$. Capillary electrophoresis (CE) has been widely used for the analysis of polyphenolic compounds. Dadakova et al. [19] studied quercetin in plant samples by micellar electrokinetic capillary chromatograph. Fonseca et al. [20] determined ten polyphenolics in Chamomilla recutita by capillary electrochromatography. Sanli and Lunte [21] used capillary electrophoresis methods for determination of eleven flavonoids in chamomile and linden extracts.

In this paper, the possibility of developing a new analysis method based on the use of non-toxic chemicals in capillary electrophoresis (CE) technique for the screening of eighteen polyphenolic compounds in five types of carob pekmez samples was investigated. To the best of our knowledge this is the first such study individually analyzed eighteen and determined fifteen polyphenolics on carob pekmez by CE collected from Turkish local markets.

\section{Methods}

\subsection{Chemicals}

Gibberellic acid, catechin, syringaldehyde, sinapinic acid, isovanillic acid, gentisic acid, ferulic acid, luteolin, quercetin, kaempferol, naringenin, chlorogenic acid, $p$-coumaric acid, vanillic acid, rosmarinic acid, caffeic acid, protocatechuic acid and gallic acid were obtained from Sigma (St. Louis MO, USA). The chemical structures of eighteen polyphenolics studied are listed in Table 1.

Methanol (MeOH, HPLC grade) was purchased from Fisher Scientific (Pittsburgh, PA, USA). Sodium tetraborate $\left(\mathrm{Na}_{2} \mathrm{~B}_{4} \mathrm{O}_{7}\right)$, boric acid $\left(\mathrm{H}_{3} \mathrm{BO}_{3}\right)$ sodium hydroxide $(\mathrm{NaOH})$, butylated hydroxyanisole $(\mathrm{BHA})$ and hydrocloric acid $(\mathrm{HCl})$ were obtained from Sigma (St. Louis MO, USA).

Stock solutions of polyphenols were prepared by dissolving enough of the studied compound in $\mathrm{MeOH}(50 \mathrm{~mL})$ to give a $100 \mathrm{ppm}$ in solution. Borate buffer $(40 \mathrm{mM})$ was prepared by mixing $\mathrm{Na}_{2} \mathrm{~B}_{4} \mathrm{O}_{7}$ with $\mathrm{H}_{3} \mathrm{BO}_{3}(500 \mathrm{mM})$ in ultrapure water. All used reagents were protected from light. The prepared solutions were stored at $4{ }^{\circ} \mathrm{C}$ for several days and at $-18^{\circ} \mathrm{C}$ for long-term storage.

\subsection{Apparatus}

All separations were performed on Agilent Technologies G7100A Capillary Electrophoresis System with a diode array detector. A $55 \mathrm{~cm} \times 50 \mu \mathrm{m}$ i.d. fused silica capillary (Agilent Technologies Ext. Light Path) with an effective length of $45 \mathrm{~cm}$ was used for the analysis. Maximum wavelength was determined by diode array detector and $210 \mathrm{~nm}$ was chosen as suitable wavelength of studied compounds. A Fisher Scientific AB $15 \mathrm{pH} / \mathrm{ion}$ analyser with Fisher Scientific Accumet combination pH electrode was used. To ensure the stability and reproducibility of the potentiometric system, $\mathrm{pH}$ measurements were performed in triplicate.

\subsection{Procedures}

Phenolic acids in pekmez varieties were determined according to the CE method of Sanli and Lunte [21] with a slight modification. In the first use, the capillary was activated by flushing with $\mathrm{MeOH}(5 \mathrm{~min}), 1.0 \mathrm{M} \mathrm{HCl}(2 \mathrm{~min})$, $\mathrm{H}_{2} \mathrm{O}$ (2 min), 1.0 M NaOH (20 min), $\mathrm{H}_{2} \mathrm{O}$ (2 min), and then with buffer (20 $\mathrm{min})$, respectively. The capillary was conditioned daily by washing with $1.0 \mathrm{M} \mathrm{NaOH}$ (20 min), $\mathrm{H}_{2} \mathrm{O}$ (2 min) and finally running buffer (20 min). Between each analysis, the capillary was flushed with $1.0 \mathrm{M} \mathrm{NaOH}$ (3 $\mathrm{min}), \mathrm{H}_{2} \mathrm{O}(2 \mathrm{~min}$ ) and then the running buffer ( $3 \mathrm{~min}$ ), 
Table 1 Chemical structure of studied polyphenolic compounds

\section{Compounds}

Gallic acid

$\mathrm{p} K_{\mathrm{a} 1}=4.24 \pm 0.04$

$\mathrm{p} K_{\mathrm{a} 2}=8.27 \pm 0.06$

$\mathrm{p} K_{\mathrm{a} 3}=9.23 \pm 0.20[25]$

CAS No : 149-91-7

\section{Chemical Structure}<smiles>O=C(O)c1cc(O)c(O)c(O)c1</smiles>

$\mathrm{C}_{7} \mathrm{H}_{6} \mathrm{O}_{5} \quad$ MW: $170.12 \mathrm{~g} \mathrm{~mol}^{-1}$
Caffeic acid

$\mathrm{p} K_{\mathrm{a} 1}=4.47 \pm 0.04$

$\mathrm{p} K_{\mathrm{a} 2}=8.32 \pm 0.01[25]$

CAS No : 331-39-5<smiles>O=C(O)/C=C/c1ccc(O)c(O)c1</smiles>

$\mathrm{C}_{9} \mathrm{H}_{8} \mathrm{O}_{4}$

\section{Sinapinic acid \\ $\mathrm{p} K_{\mathrm{a} 1}=4.27$ \\ $\mathrm{p} K_{\mathrm{a} 2}=9.20[26]$}

CAS No : 530-59-6<smiles>COc1cc(/C=C/C(=O)O)cc(OC)c1O</smiles>

$\mathrm{C}_{11} \mathrm{H}_{12} \mathrm{O}_{5} \quad$ MW: $224.1 \mathrm{~g} \mathrm{~mol}^{-1}$

$$
\begin{aligned}
& \text { Isovanillic acid } \\
& \begin{array}{l}
\mathrm{p} K_{\mathrm{a} 1}=4.24 \pm 0.08 \\
\mathrm{p} K_{\mathrm{a} 2}=9.58 \pm 0.09[25]
\end{array}
\end{aligned}
$$

CAS No : 645-08-9<smiles>COc1ccc(C(=O)O)cc1O</smiles>

$\mathrm{C}_{8} \mathrm{H}_{8} \mathrm{O}_{4}$
MW: $168.15 \mathrm{~g} \mathrm{~mol}^{-1}$

Gibberellic acid

$\mathrm{p} K_{\mathrm{a}}=4.0[27]$

CAS No : 77-06-5

$\mathrm{C}_{19} \mathrm{H}_{22} \mathrm{O}_{6} \quad \mathrm{MW}=346.38 \mathrm{~g} \mathrm{~mol}^{-1}$ 
Table 1 (continued)

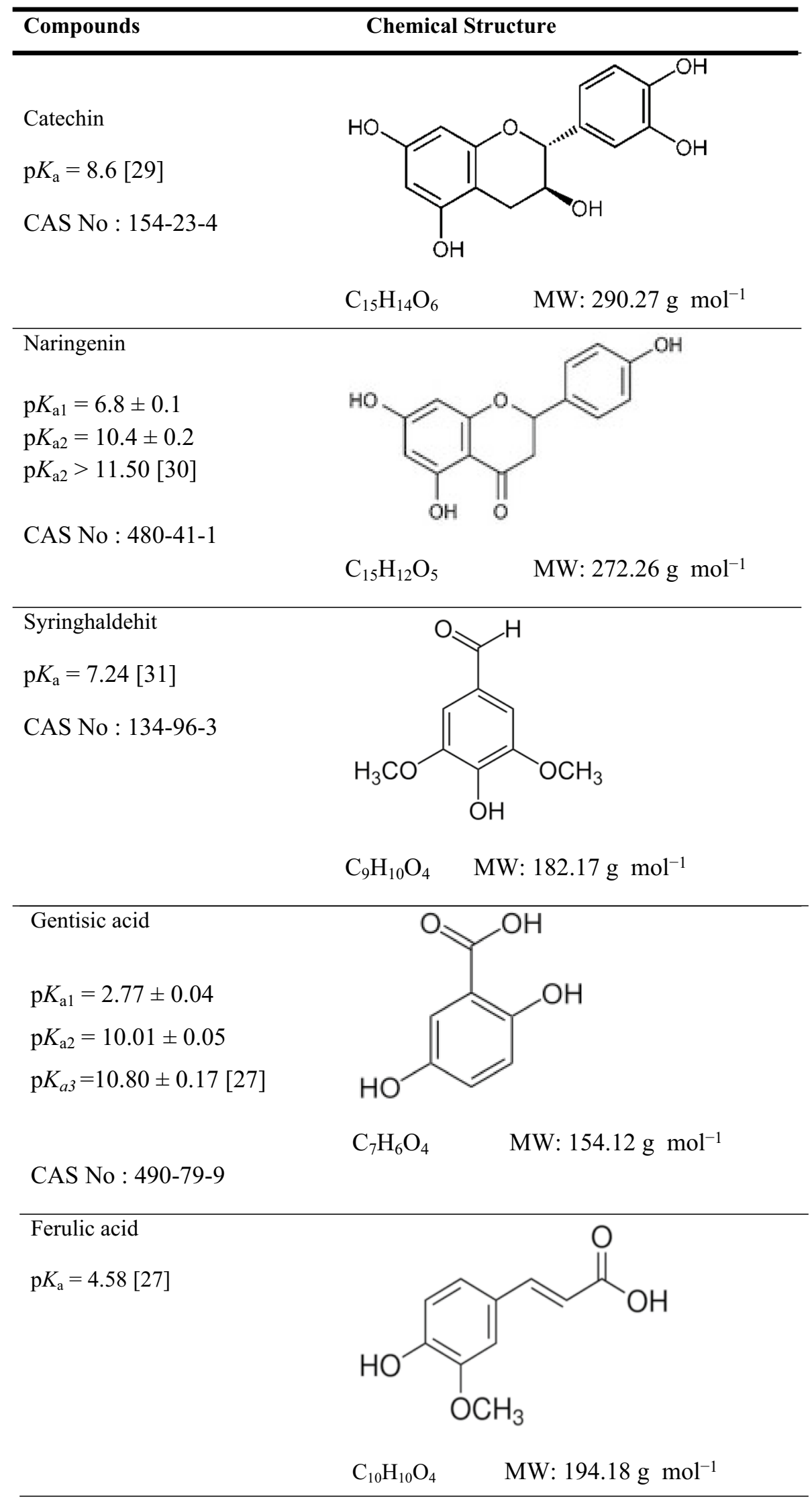




Compounds

Luteolin

$\mathrm{p} K_{\mathrm{a} 1}=5.99 \pm 0.32$

$\mathrm{p} K_{\mathrm{a} 2}=8.40 \pm 0.42[32]$<smiles>O=c1cc(-c2ccc(O)c(O)c2)oc2cc(O)cc(O)c12</smiles>

CAS No : 491-70-3

$$
\mathrm{C}_{15} \mathrm{H}_{10} \mathrm{O}_{6} \quad \text { MW: } 286.24 \mathrm{~g} \mathrm{~mol}^{-1}
$$

Quercetin

$\mathrm{p} K_{\mathrm{a} 1}=5.87 \pm 0.14$

$\mathrm{p} K_{\mathrm{a} 2}=8.48 \pm 0.09[32]$

CAS No : 117-39-5<smiles>O=c1c(O)c(-c2ccc(O)c(O)c2)oc2cc(O)cc(O)c12</smiles>

$\mathrm{C}_{15} \mathrm{H}_{10} \mathrm{O}_{7}$

MW: $302.24 \mathrm{~g} \mathrm{~mol}^{-1}$ 
Table 1 (continued)

\begin{tabular}{l} 
Compounds \\
\hline $\mathrm{p}$-Coumaric acid \\
$\mathrm{CAS} K_{\mathrm{a} 1}=4.55$ \\
$\mathrm{p} K_{\mathrm{a} 2}=8.84$ [26]; $: 501-98-4$ \\
$\mathrm{CAS} K_{\mathrm{a}}=3.13$ [31]
\end{tabular}

respectively. Prior to use, buffer solutions were filtered through $0.25 \mu \mathrm{m}$ membrane filters (Millipore, Bedford, $\mathrm{MA}$ ) and degassed by ultra-sonication for about $10 \mathrm{~min}$. Buffer, containing $40 \mathrm{mM} \mathrm{Na}_{2} \mathrm{~B}_{4} \mathrm{O}_{7}$, was adjusted to $\mathrm{pH} 8.4$ with $0.5 \mathrm{M} \mathrm{H}_{3} \mathrm{BO}_{3}$. The voltage was $30 \mathrm{kV}$, pressure injection was at 50 mbar for $5 \mathrm{~s}$, and the detection was performed at $210 \mathrm{~nm}$.

\subsection{Sample preparations}

Five samples of different types of carob pekmez were purchased from local supermarkets in Uşak, Turkey. All carob pekmez samples were stored in the dark at $+4{ }^{\circ} \mathrm{C}$ until analysis. Sample preparation was optimized according to the method of Alasalvar et al. [22].

$2.0 \mathrm{~g}$ sample was weighed into a $50 \mathrm{~mL}$ test tube and homogenized for $3 \mathrm{~min}$. In $20 \mathrm{~mL}$ of methanol mixture containing $2 \mathrm{~g} / \mathrm{L}$ of butylated hydroxyanisole $(\mathrm{BHA})$ and $10 \%$ acetic acid $(85: 15, \mathrm{v} / \mathrm{v})$. Subsequently, all sample extracts were ultra-sonicated for $30 \mathrm{~min}$, brought to $30 \mathrm{~mL}$ with extraction solvent and stirred. The samples were then centrifuged at $1000 \mathrm{~g}$ for $15 \mathrm{~min}$ and finally $2 \mathrm{~mL}$ of the supernatant were filtered through a GELMAN Acrodisc LC13 PVDV 0.45- $\mu \mathrm{m}$ pore size syringe filter (PALL Life Sciences, Ann Arbor, Mich., U.S.A.) for the LC analysis of free phenolic acids.

\section{Results}

\subsection{Effects of $\mathrm{pH}$ and the separation voltage}

The mechanism of separation is based on differences between the charge-to-size ratios of the studied compounds in CE technique. The studied polyphenolics have at least one ionizing group and ionization of this group is one of the main factors determining the electrophoretic mobility [23]. Ionization constant $\left(p K_{\mathrm{a}}\right)$ values reported in the literature in water medium are given in Table 1 [24-31].

Borate buffer was used as buffer in this study because borate can be chelated with analytes to form more soluble complex anions [32]. The $\mathrm{pH}$ values of the migration time 
were examined over the range of 8.4-9.1 (by using $40 \mathrm{mM}$ $\mathrm{Na}_{2} \mathrm{~B}_{4} \mathrm{O}_{7}-0.5 \mathrm{M} \mathrm{H}_{3} \mathrm{BO}_{3}$ as a buffer). The voltage was $30 \mathrm{kV}$. In Fig. 1, the electropherograms of eighteen polyphenolics studied in different three $\mathrm{pH}$ values were given. Absorbance of the phenolic compounds was strongly influenced by the $\mathrm{pH}$ conditions. The areas of studied compounds in the region $\mathrm{pH} 8.4-9.1$ at 320,280 and $210 \mathrm{~nm}$ were checked and higher areas were observed at $210 \mathrm{~nm}$, so $210 \mathrm{~nm}$ was preferred for screening absorbance. When the $\mathrm{pH} 9.1$ was investigated, it can be seen that there is tailing of polyphenolic compounds and isovanilic acid, gentisic acid and ferulic acid were not separated. The same positions could be said for $p$-coumaric and vanilic acid. $\mathrm{pH} 8.7$ was better than $\mathrm{pH} 9.1$ for the separations of isovanilic acid, gentisic acid and ferulic acid but there was a problem for kaempferol, chlorogenic acid and $p$-coumaric acid separations. Additionally, the observed migration times at different $\mathrm{pH}$ values can be changed as uncharged and fully ionized forms. A solute has its maximum electrophoretic mobility when it is fully ionized, has minimum mobility in its uncharged form, and has an intermediate mobility in the $\mathrm{pH}$ region surrounding its $\mathrm{pK}_{\mathrm{a}}$ value. Thus, different migration times were observed at different $\mathrm{pH}$ values as seen in Fig. 1. Some of the polyphenolic compounds are more sensitive to oxidative degradation at higher $\mathrm{pH}$ and long separation times. Also, increasing the concentration of borate buffer results in increased migration times. Good resolution was achieved using $40 \mathrm{mM}$ borate buffer with the shortest separation time. The optimum $\mathrm{pH}$ was determined to be $\mathrm{pH} 8.4$ on the basis of good resolution, selectivity and peak shapes of compounds within a relatively short analysis time (17 $\mathrm{min}$ ).
Fig. 1 Electropherogram of studied polyphenolic compounds at different buffer $\mathrm{pH}$. Running buffer $40 \mathrm{mM}$ $\mathrm{Na}_{2} \mathrm{~B}_{4} \mathrm{O}_{7}-0.5 \mathrm{M} \mathrm{H}_{3} \mathrm{BO}_{3}$ solution; concentration of standards was about $20 \mu \mathrm{g} / \mathrm{mL}$; applied voltage $30 \mathrm{kV}$; detection UV absorbance at $210 \mathrm{~nm}$; uncoated fused silica capillary $55 \mathrm{~cm}$ (45 cm to detector) $50 \mu \mathrm{m}$ i.d.; pressure injection, 50 mbar for $5 \mathrm{~s}$; ambient temperature $\left(25^{\circ} \mathrm{C}\right)$. Peaks represent (1) Gibberellic acid, (2) Catechin, (3) Naringenin, (4) Syringaldehyde, (5) Sinapinic acid, (6) Isovanillic acid, (7) Gentisic acid, (8) Ferulic acid, (9) Kaempferol, (10) Chlorogenic acid, (11) $p$-Coumaric acid, (12) Vanilic acid, (13) Luteolin, (14) Quercetin, (15) Rosmarinic acid, (16) Caffeic acid, (17) Gallic acid, (18) Protocatechuic acid
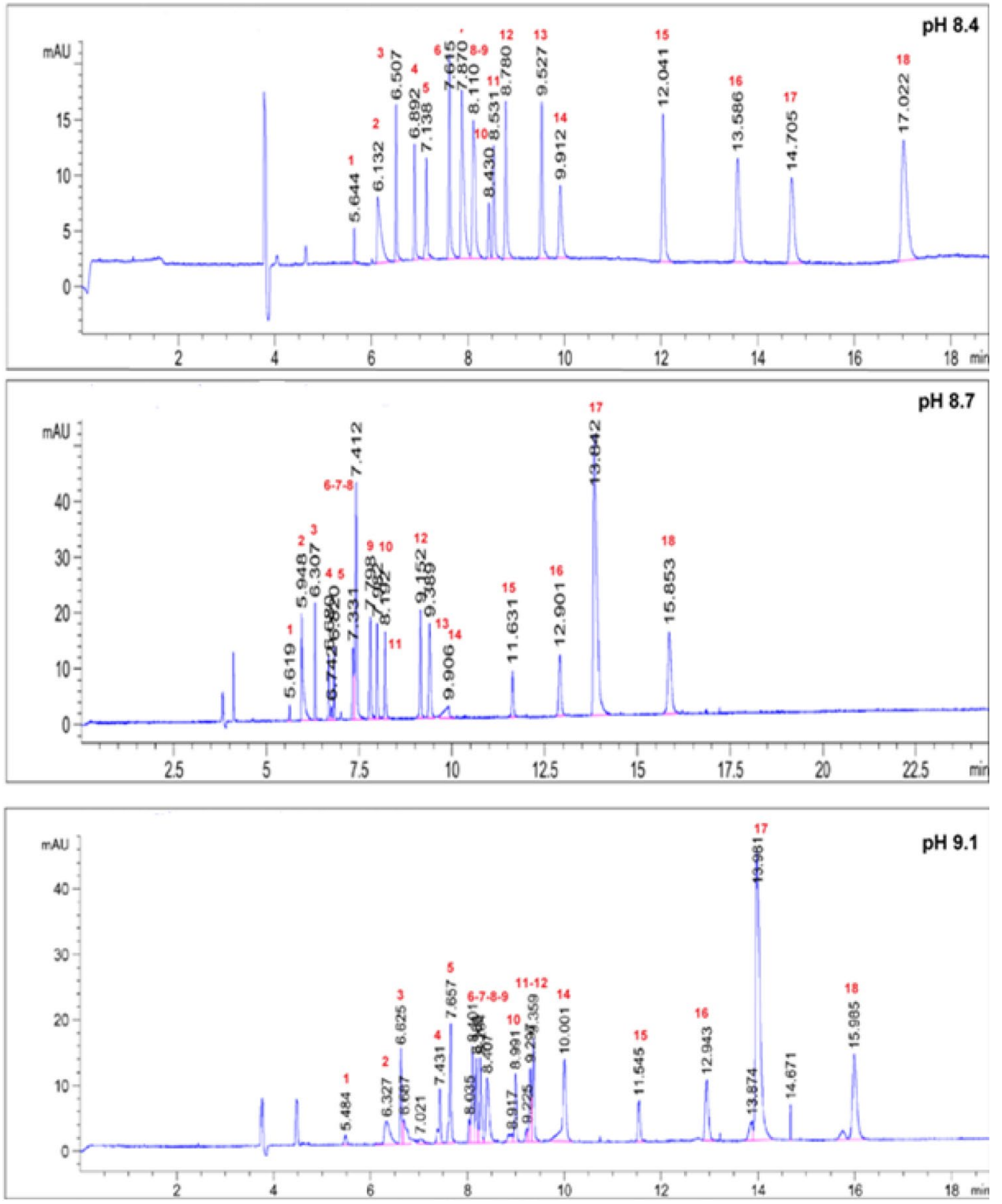
The effect of separation voltage on migration time of the analytes was also investigated. The optimum voltage was determined by performing runs at increasing voltages (20, 28 and $30 \mathrm{kV}$ ). In Fig. 2, gallic acid, peak number 4, known as the main compound in carob molasses, appears to have a migration time of $23.92,15.59$ and $14.17 \mathrm{~min}$ at separation voltages of 20,28 and $30 \mathrm{kV}$, respectively. All four compounds (syringaldehyde, synapinic acid, isovanilic acid and gallic acid) were found to decrease migration times as the separation voltage was increased. On the other hand, it was observed that the application of the separation voltage of $28 \mathrm{kV}$ and $30 \mathrm{kV}$ did not result in a significant difference in the separation of the three compounds. Accordingly, considering the short analysis time, the optimum separation voltage was decided to be $30 \mathrm{kV}$.

Optimum conditions for the separation of all eighteen polyphenols from the above experiments were determined to be; $40 \mathrm{mM}$ borate, $\mathrm{pH} 8.4$ with an applied voltage of $30 \mathrm{kV}$. A typical electropherogram for all studied analytes is given in Fig. 3; separation is achieved within $17 \mathrm{~min}$.
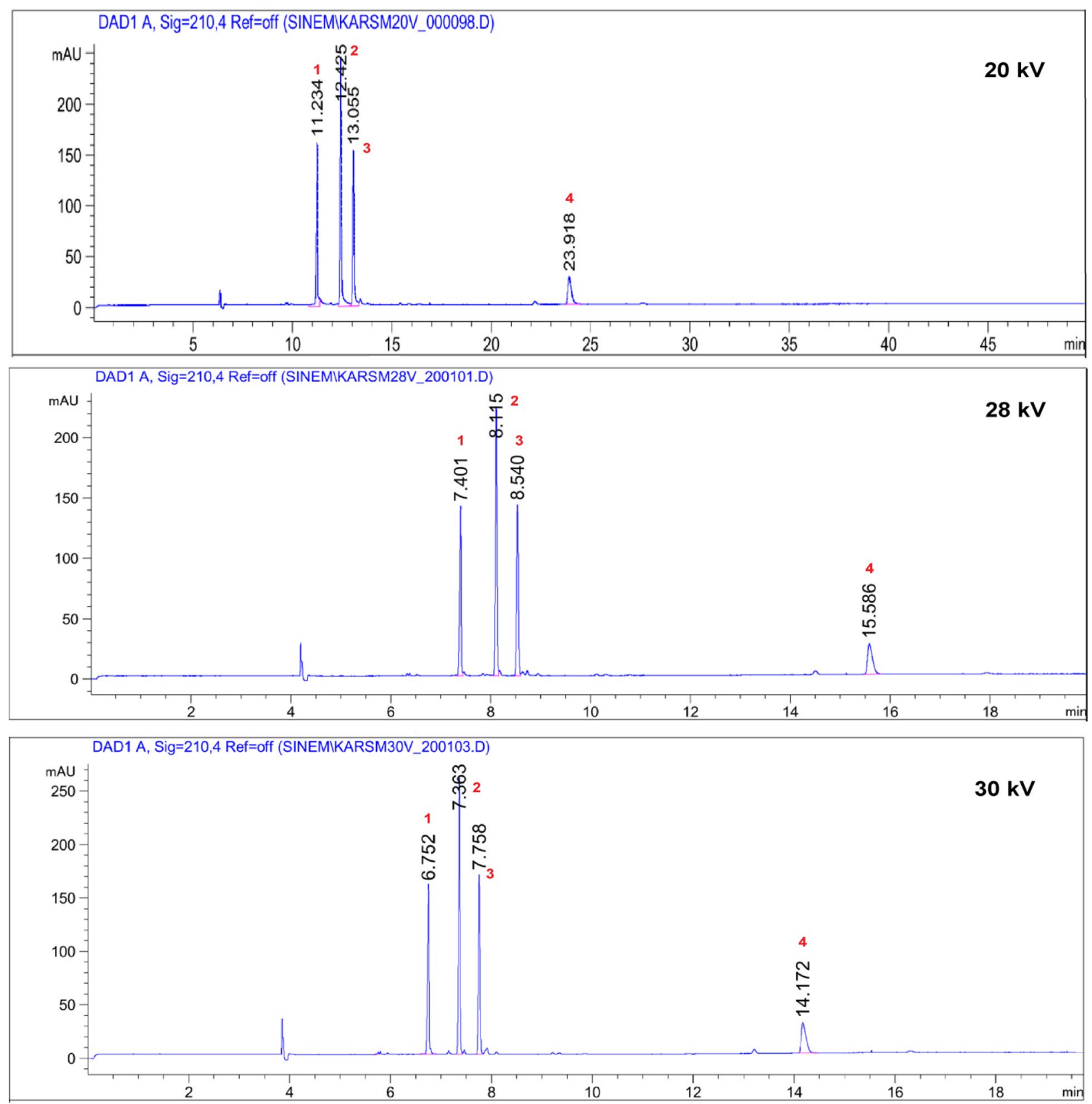

Fig. 2 Electropherogram of $100 \mu \mathrm{g} / \mathrm{mL}$ identified critical peak pairs at different voltages (20-28-30 kV). Running buffer pH was 8.4. The other experimental conditions were the same as shown for Fig. 1. (1) Syringaldehyde (2) Sinapinic acid (3) Isovanillic acid (4) Gallic acid 


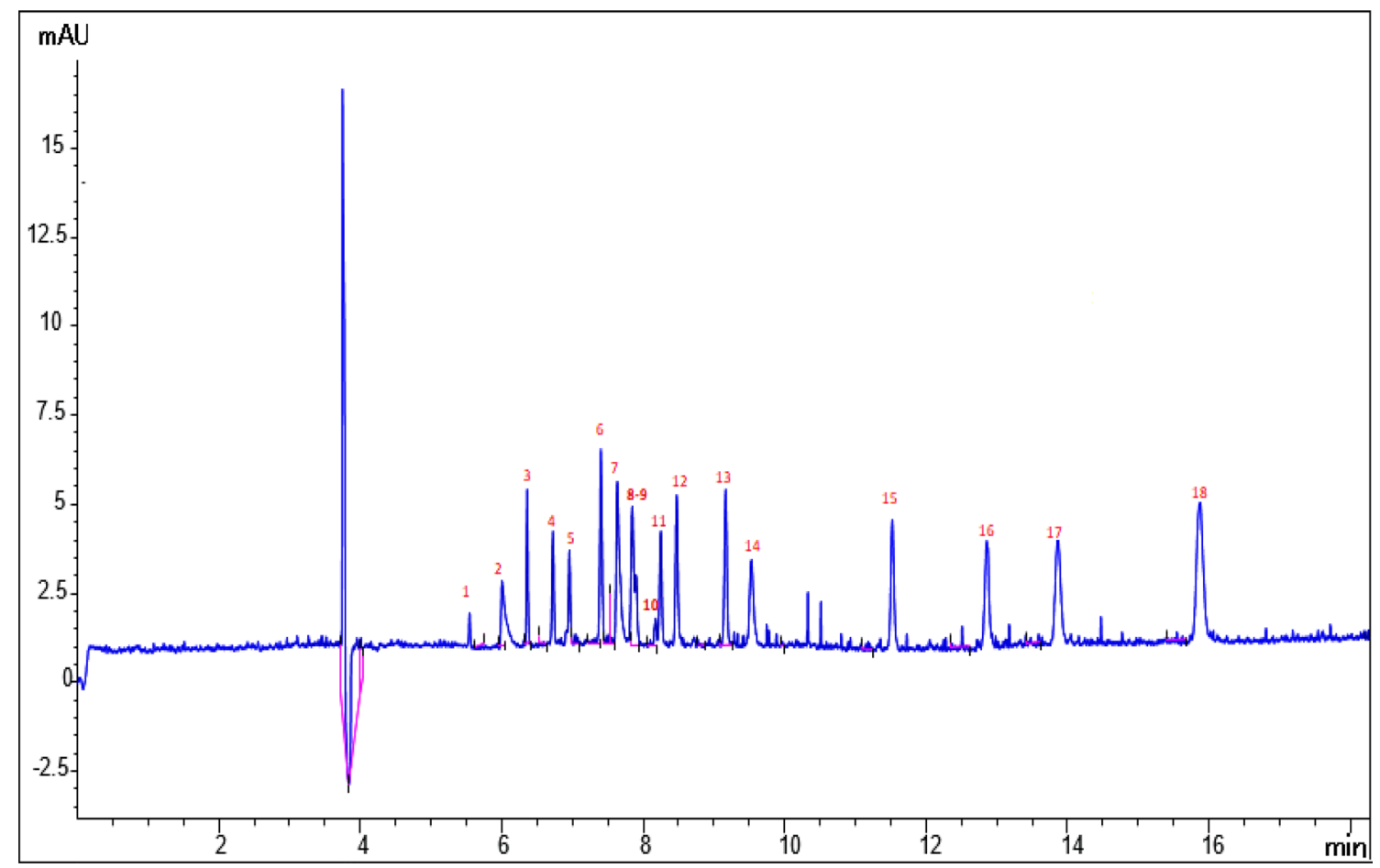

Fig. 3 Electropherogram of eighteen polyphenolic compounds under optimum conditions. Running buffer $40 \mathrm{mM}$ sodium tetraborate solution (pH 8.4); uncoated fused silica capillary $55 \mathrm{~cm}(45 \mathrm{~cm}$ to detector) $\times 50 \mu \mathrm{m}$ i.d.; applied voltage $30 \mathrm{kV}$; detection UV absorbance at $210 \mathrm{~nm}$; pressure injection, 50 mbar for $5 \mathrm{~s}$; ambient temperature $\left(25^{\circ} \mathrm{C}\right)$. Peaks represent in the figure are the same as Fig. 1

Table 2 Statistical evaluation of the calibration data of studied phenolics by CE-DAD $(n=5)$

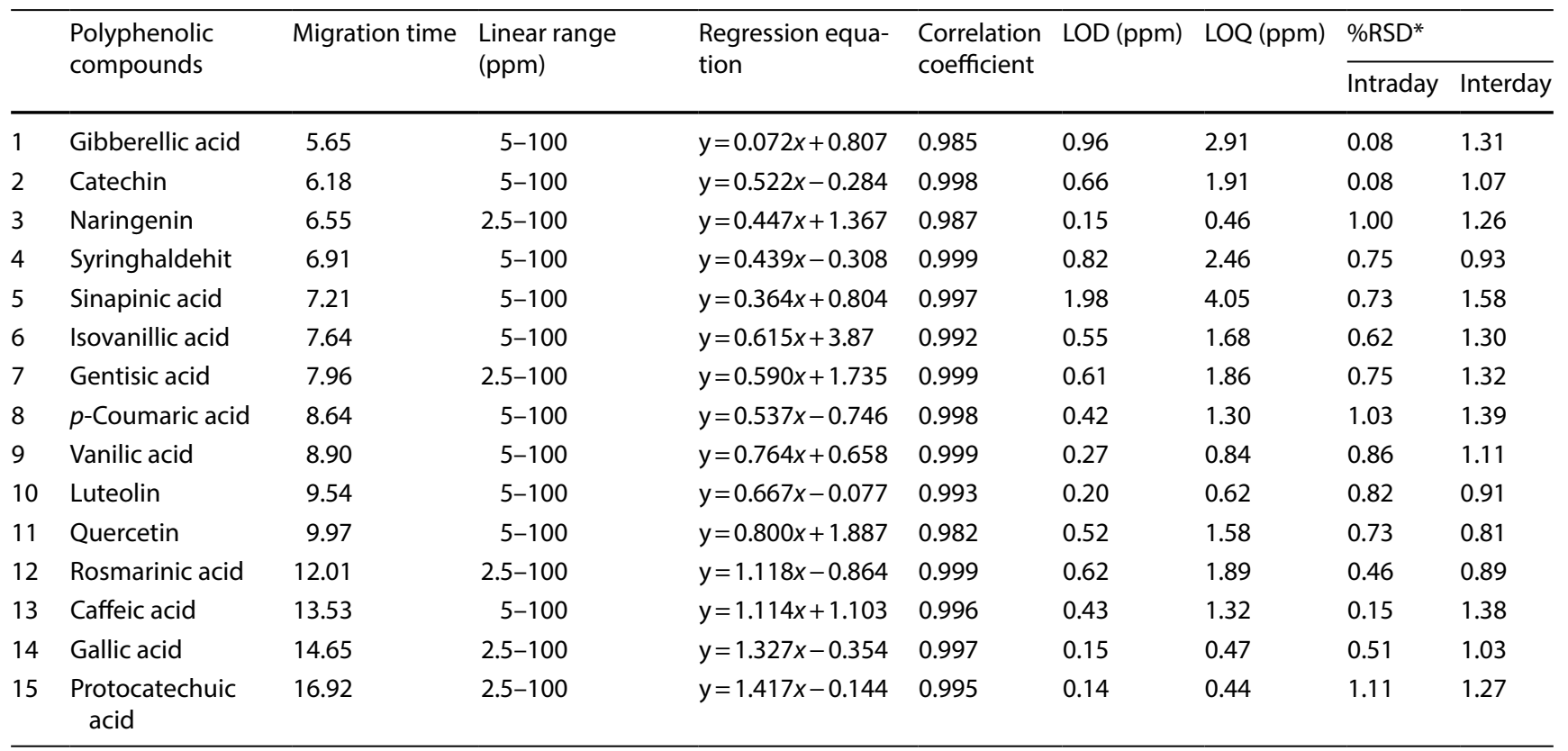

${ }^{*}$ Calculated on the basis of peak area 
Fig. 4 Electropherograms of some carob pekmez samples studied; the experimental conditions were the same as shown for Fig. 3. (1) Gentisic acid, (2) Vanillic acid, (3) Luteolin, (4) Gallic acid
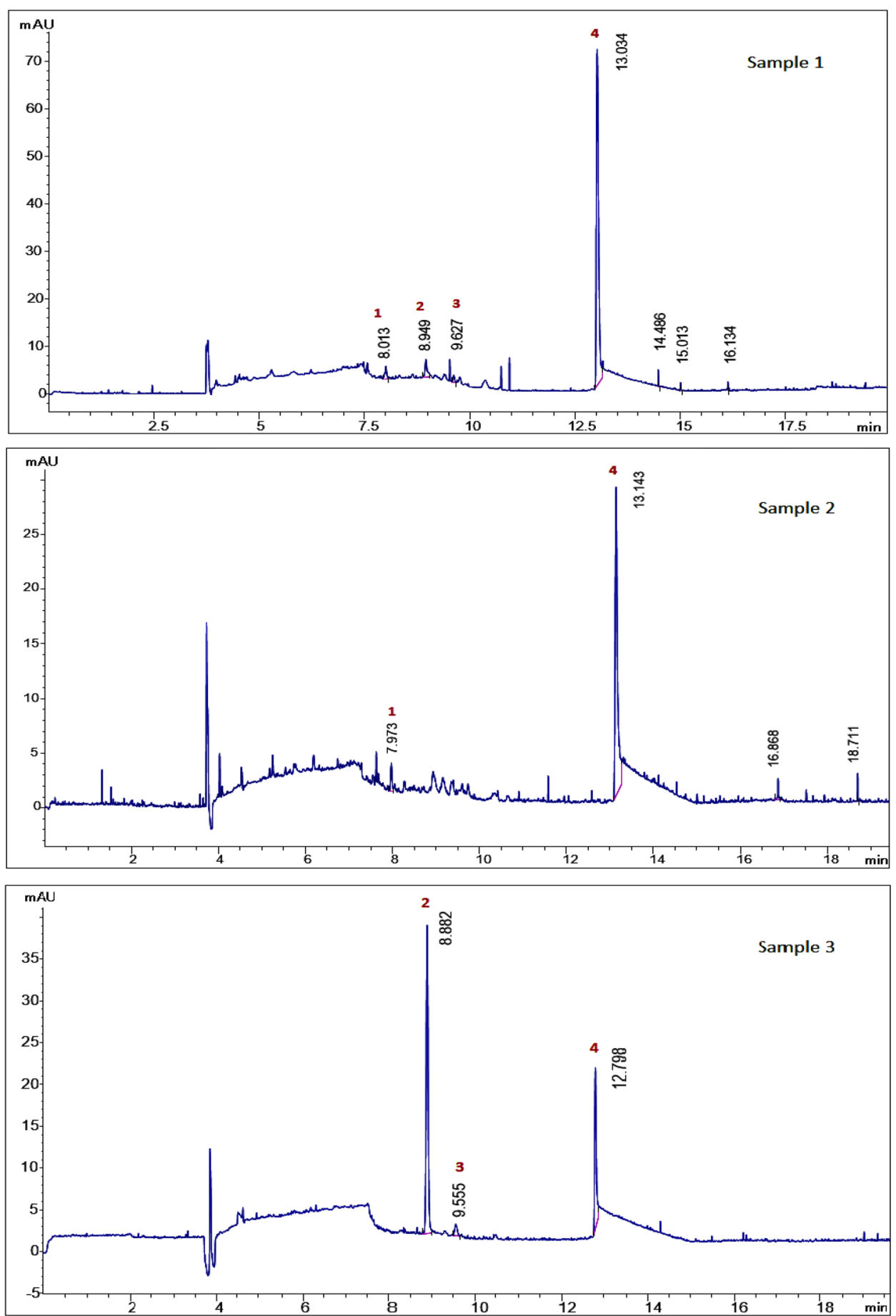

\subsection{Linearity, repeatability and detection limits}

Validation parameters were determined by testing a series of standard mixture solutions of the analytes studied [33]. The linearity range is expressed in term of correlation coefficient of linear regression analysis. The linearity range for studied compounds were assessed by analysis of five independent levels of calibration curve in range of 2.5 or $5-100 \mu \mathrm{g} / \mathrm{mL}(n=5)$. Five working standard solutions of compounds were injected and analysed. For the calculation of linearity, plotting of the peak area versus concentration of the compounds were used. The calibration curves were obtained by linear least squares regression. The developed method was found to be 
Table 3 Phenolic composition of carob pekmez samples

\begin{tabular}{|c|c|c|c|c|c|c|}
\hline \multirow{2}{*}{$\begin{array}{l}\text { Polyphenolic } \\
\text { compounds }\end{array}$} & \multicolumn{5}{|c|}{ Carob pekmez samples $\left(\mu \mathrm{g} \mathrm{g}^{-1}\right)^{*}$} & \multirow[t]{2}{*}{ Recovery (\%) } \\
\hline & Sample 1 & Sample 2 & Sample 3 & Sample 4 & Sample 5 & \\
\hline Gallic acid & $3021.65 \pm 105.39$ & $1277.96 \pm 144.24$ & s746.54 \pm 163.17 & $3065.23 \pm 32.39$ & $2845.22 \pm 296.20$ & 92.73 \\
\hline Vanilic acid & $100.65 \pm 7.22$ & ND & $2031.93 \pm 216.9$ & ND & ND & 99.20 \\
\hline Gentisic acid & $96.83 \pm 7.22$ & $106.07 \pm 11.46$ & ND & ND & ND & 99.50 \\
\hline Luteolin & $88.16 \pm 1.23$ & ND & $117.14 \pm 15.19$ & ND & $191.42 \pm 12.28$ & 98.99 \\
\hline
\end{tabular}

$N D$ not detectable

${ }^{*}$ All results are given as mean \pm SD (standard deviation)

precise as RSD values. $30 \mu \mathrm{g} / \mathrm{mL}$ concentration was prepared six times. The solutions were injected in CE system and analyzed by the proposed method. The area of the peak was measured at $210 \mathrm{~nm}$ and \%RSD was calculated. The validation data are shown in Table 2. It has been observed that the resolutions of critical peak pairs (ferulic acid, kaempferol and chlorogenic acid) were lower from the others. For these three compounds, enough resolution values could not be obtained. Therefore, no calibration plots were drawn for ferulic acid, kaempferol and chlorogenic acid. Moreover, these compounds were not detected in carob pekmez samples.

The developed method represented good linearity based on correlation coefficients $>0.98$ for all studied compounds. The LOD and LOQ were calculated as $3.3 \mathrm{~s} \mathrm{~m}^{-1}$ and $10 \mathrm{~s} \mathrm{~m}^{-1}$, where $\mathrm{s}$ is the standard deviation of response and $\mathrm{m}$ is the slope of the corresponding calibration curve $[34,35]$. The LOD and LOQ values calculated for phenolic substances ranged from 0.14 to $1.98 \mathrm{ppm}$, and 0.44-4.05 ppm, respectively. However, LOD and LOQ values of sinapinic acid were higher than other phenolic substances. It is thought to be due to the chemical structure of the compound.

In the literature, there is no method for the simultaneous determination of these compounds by capillary electrophoresis for molasses samples. Furthermore, the developed method provides combination of improved detection limits, shapes and faster analysis time.

\subsection{Sample analysis and recovery}

The optimized and validated methodology was applied to quantification of the polyphenolics in five carob pekmez samples collected from Turkish local markets. Typical electropherogram of carob pekmez samples are shown in Fig. 4. All peak identities were determined by co-elution with standards, standard addition to samples and comparison of absorbance spectra with standard spectra. The contents of the five extracts were quite different. Four of the studied compounds were detected (gallic acid, vanilic acid, gentisic acid and luteoline) under the optimum conditions. As mentioned previously, gallic acid was found to be high in carob pekmez samples (Table 3). On the other hand, only gallic acid can be detected in sample 4, while a higher amount of vanilic acid is detected in sample 3 . The concentration of the analytes in the studied samples were obtained using peak areas from the calibration curve. Known amounts of analytes (different for each compounds) were added to samples and recovery values were calculated using peak area from the calibration curve. The recoveries for these compounds were determined to be over $95 \%$. Each sample was analyzed in triplicate and the recovery results demonstrated that developed method is appropriate for real sample analysis.

\section{Discussion}

Although several methods have been reported for determination of the different types of phenolics, to the best of our knowledge, there are no methods yet for simultaneous screening of eighteen phenolics by $C E$ coupled with diode array detection (DAD) in carob pekmez samples. In this work, green, simple, fast, effective and new CE-DAD method has been developed and applied. Eighteen phenolic compounds were analyzed and fifteen compounds were determined within 17 min without using organic solvent in a short time such as $17 \mathrm{~min}$. Also, this method has been found to be reproducible and highly sensitive in commercially available carob samples. For the validity of the developed method, recovery experiments were performed and the values were found to be high. The proposed method promises to be applicable to the identification and determination of the studied phenolics in other plant extracts as well. 
The results presented in this work suggest that carob pekmez serve as a good source of natural antioxidant that could potentially be used in food and nutraceutical supplement formulations. Even though all carob pekmez samples showed similar chemical characteristics, small differences in their phenolic contents may be due to the differences in production style, raw material and origin of the fruit etc.

Acknowledgements We would like to thank the TÜBITAK (The Scientific and Technological Research Council of Turkey) (Project No. 115Z053) for financial support.

Funding This research did not receive any specifc grant from funding agencies in the public, commercial, or not-for-profit sectors.

\section{Compliance with ethical standards}

Conflict of interest The authors declare that they have no conflict of interest.

Human and animal rights This article does not contain any studies with human participants or animals performed by any of the authors.

Informed consent Not applicable.

\section{References}

1. Petit MD, Pinilla JM (1995) Production and purification of a sugar syrup from carob pods. Lebensm-Wiss Technol 28:145-152. https://doi.org/10.1016/S0023-6438(95)80027-1

2. Battle I, Tous J (1997) Carob Tree (Ceratonia silique L.). International Plant Genetic Resources Institute, Rome

3. Benkovic M, Belscak-Cvitanovic A, Bauman I, Komes D, Srecec $S$ (2017) Flow properties and chemical composition of carob (Ceratonia siliqua L.) flours as related to particle size and seed presence. Food Res Int 100:211-218. https://doi.org/10.1016/j. foodres.2017.08.048

4. Santos M, Rodrigues A, Teixeira JA (2005) Production of dextran and fructose from carob pod extract and cheese whey by Leuconostoc mesenteroides NRRL B512 (f). Biochem Eng J 25:1-5. https://doi.org/10.1016/j.bej.2005.01.022

5. Yousif AK, Alghzawi HM (2000) Processing and characterization of carob powder. Food Chem 69:283-287. https://doi. org/10.1016/S0308-8146(99)00265-4

6. Sengül M, Ertugay MF, Sengül M, Yüksel Y (2007) Rheological characteristics of carob pekmez. Int J Food Prop 10:39-46. https ://doi.org/10.1080/10942910600627996

7. Simsek A (2000) Research on the composition of different fruit concentrate. MSD Thesis, Ankara University Graduate School of Natural and Applied Sciences, Ankara, Turkey

8. Kumazawa S, Taniguchi M, Suzuki Y, Shimura M, Kwon M, Nakayama T (2002) Antioxidant activity of polyphenols in carob pods. J Agric Food Chem 50:373-377. https://doi.org/10.1021/jf010 $938 r$

9. Owen RW, Haubner R, Hull WE, Erben G, Spiegelhalder B, Bartsch $\mathrm{H}$, Haber B (2003) Isolation and structure elucidation of the major individual polyphenols in carob fibre. Food Chem Toxicol 41:1727-1738. https://doi.org/10.1016/S0278-6915(03)00200-X
10. Shahidi F, Naczk M (1995) Food phenolics: sources, chemistry, effects, applications. Technomic Publishing Co, Inc., Lancaster

11. Häkkinen $S$, Heinonen $M$, Kärenlampi $S$, Mykkänen $H$, Ruuskanen J, Tärränen R (1999) Screening of selected flavonoids and phenolic acids in 19 berries. Food Res Int 32:345-353. https://doi. org/10.1016/S0963-9969(99)00095-2

12. Zuo Y, Wang C, Zhan J (2002) Separation, characterization, and quantitation of benzoic and phenolic antioxidants in American cranberry fruit by GC-MS. J Agric Food Chem 50:3789-3794. https://doi.org/10.1021/jf020055f

13. Ayaz FA, Hayirlioglu-Ayaz S, Gruz J, Novak O, Strnad M (2005) Separation, characterization, and quantitation of phenolic acids in little known blueberry (Vaccinium arctostaphylos L.) fruit by HPLC-MS. J Agric Food Chem 53:8116-8122. https:// doi.org/10.1021/jf058057y

14. Koel M, Kaljurand M (2006) Application of the principles of green chemistry in analytical chemistry. Pure Appl Chem 78:19932002. https://doi.org/10.1351/pac200678111993

15. Anastas PT (1999) Green chemistry and the role of analytical methodology development. Crit Rev Anal Chem 29:167-175. https://doi.org/10.1080/10408349891199356

16. Armenta S, Garrigues S, De La Guardia M (2008) Green analytical chemistry. Trac-Trend Anal Chem 27:497-511. https://doi. org/10.1016/j.trac.2008.05.003

17. Kirchhoff MM (2005) Promoting sustainability through green chemistry. Resour Conserv Recycl 44:237-243. https://doi. org/10.1016/j.resconrec.2005.01.003

18. Warner JC, Cannon AS, Dye KM (2004) Green chemistry. Environ Impact Asses 24:775-799. https://doi.org/10.1016/j. eiar.2004.06.006

19. Dadakova E, Prochazkova E, Krizek M (2001) Application of micellar electrokinetic capillary chromatography for quantitative analysis of quercetin in plant materials. Electrophoresis 22:1573-1578. https://doi.org/10.1002/1522-2683(20010 5)22:8\%3c1573:AID-ELPS1573\%3e3.0.CO;2-B

20. Fonseca FN, Tavares MFM, Horvath C (2007) Capillary electrochromatography of selected phenolic compounds of Chamomilla recutita. J Chromatogr A 1154:390-399. https:// doi.org/10.1016/j.chroma.2007.03.106

21. Sanli S, Lunte C (2014) Determination of eleven flavonoids in chamomile and linden extracts by capillary electrophoresis. Anal Methods 6:3858-3864. https://doi.org/10.1039/c3ay4 $1878 \mathrm{~b}$

22. Alasalvar C, Al-Farsi M, Shahidi F (2005) Compositional characteristics and antioxidant components of cherry laurel varieties and pekmez. J Food Sci 70:47-52. https://doi. org/10.1111/j.1365-2621.2005.tb09064.x

23. Morin PH, Archambault JC, Andre P, Dreux M, Gaydou E (1997) Separation of hydroxylated and methoxylated flavonoids by micellar electrokinetic capillary chromatography. Determination of analyte partition coefficients between aqueous and sodium dodecyl sulfate micellar phases. J Chromatogr A 791:289-297. https://doi.org/10.1016/S0021-9673(97)00774 $-7$

24. Erdemgil FZ, Şanli S, Şanli N, Özkan G, Barbosa J, Guiteras J, Beltran JL (2007) Determination of $\mathrm{p} K_{\mathrm{a}}$ values of some hydroxylated benzoic acids in methanol-water binary mixtures by LC methodology and potentiometry. Talanta 72:489-496. https ://doi.org/10.1016/j.talanta.2006.11.007

25. Ozkorucuklu SP, Beltran JL, Fonrodona G, Barrón D, Alsancak G, Barbosa J (2009) Determination of dissociation constants of some hydroxylated benzoic and cinnamic acids in water from mobility and spectroscopic data obtained by CE-DAD. J Chem Eng Data 54:807-811. https://doi.org/10.1021/je800595x 
26. Serjeant EP, Dempsey B (1979) lonisation constants of organic acids in aqueous solution. IUPAC Chem Data Ser No. 23. NY, NY: Pergamon

27. Tomlin CDS (1997) (ed.). The pesticide manual—world compendium, 11 th ed., British Crop Protection Council, Surrey, England

28. Tungjai M, Poompimon W, Loetchutinat C, Kothan S, Dechsupa N, Mankhetkorn S (2008) Spectrophotometric characterization of behavior and the predominant species of flavonoids in physiological buffer: determination of solubility, lipophilicity and anticancer efficacy. Open Drug Deliv J 2:10-19. https://doi. org/10.2174/1874126600802010010

29. Serra H, Mendes T, Bronzea MR, Simplicio AL (2008) Prediction of intestinal absorption and metabolism of pharmacologically active flavones and flavanones. Bioorg Med Chem 16:40094018. https://doi.org/10.1016/j.bmc.2008.01.028

30. Physico-chemical calculations \& predictions module developed by ChemAxon. https://chemaxon.com/products/calculator s-and-predictors. Accessed 10 July 2019

31. Ramesova S, Sokolova R, Degano I, Bulıckova J, Zabka J, Gal M (2012) On the stability of the bioactive flavonoids quercetin and luteolin under oxygen-free conditions. Anal Bioanal Chem 402:975-982. https://doi.org/10.1007/s00216-011-5504-3

32. Hoffstetter-Kuhn S, Paulus A, Gassmann E, Michael H (1991) Influence of borate complexation on the electrophoretic behavior of carbohydrates in capillary electrophoresis. Anal Chem 63:1541-1546. https://doi.org/10.1021/ac00015a009

33. $\mathrm{CH}$, Topic $\mathrm{Q} 2 \mathrm{~A}$ validation of analytical procedures methodology $\mathrm{PMP} / \mathrm{ICH} / 281 / 95$

34. Riley CM, Rosanske TW (1996) Development and validation of analytical methods. Elsevier, New York

35. Swartz ME, Krull IS (1997) Analytical method development and validation. Marcel Dekker Inc., New York

Publisher's Note Springer Nature remains neutral with regard to jurisdictional claims in published maps and institutional affiliations. 